International Review of Research in Open and Distributed Learning Volume 21, Number 1

January - 2020

\title{
Studying Learner Behavior in Online Courses With Free- Certificate Coupons: Results From Two Case Studies
}

Joshua Littenberg-Tobias, Jose Ruiperez Valiente, and Justin Reich

Massachusetts Institute of Technology

\begin{abstract}
The relationship between pricing and learning behavior is an important topic in research on massive open online courses (MOOCs). We report on two case studies where cohorts of learners were offered coupons for free certificates to explore how price reductions might influence behavior in MOOC-based online learning settings. In Case Study 1, we compare participation and certification rates between courses with and without free-certificate coupons. In the courses with a free-certificate track, participants signed up for the verifiedcertificate track at higher rates, and completion rates among verified students were higher than in the paidcertificate track courses. In Case Study 2, we compare learner behavior within the same courses by whether they received access to a free-certificate track. Access to free certificates was associated with lower certification rates, but overall, certification rates remained high, particularly among those who viewed the courses. These findings suggest that some incentives, other than simply the cost of paying for a verifiedcertificate track, may motivate learners to complete MOOCs.
\end{abstract}

Keywords: massive open online courses, MOOCs, online learning, price elasticity, distance learning, free coupons, learning analytics 


\section{Introduction}

From the outset of massive open online courses (MOOCs), pricing was one of the field's most challenging problems. Although most MOOCs started out as free, they could not remain so indefinitely without a revenue stream (Dellarocas \& Van Alstyne, 2013), and MOOC providers needed to experiment with different pricing models (Bonvillian \& Singer, 2013). In the literature, several different pricing strategies have been suggested. For example, Baker and Passmore (2016) review a set of business strategies (crosssubsidy, third-party, "freemium," and nonmonetary) and explain how these can be applied to MOOC settings. Another proposal is to use subscription models instead of having users pay for a single certificate (Kung \& Yang, 2018). Finally, many MOOC providers now offer online master's degrees and other credential programs where certain content, assessments, support services, and credential eligibility requires a fee (Reich \& Ruipérez-Valiente, 2019). As MOOC pricing evolves, new questions emerge about price sensitivity: What price will consumers pay to participate in MOOCs, and to what extent does introducing pricing structures change who participates in a course and how they participate?

In this work, we present two online learning case studies situated within MOOC-based technologies. In the first one ( $N=50,453$ registrants), we conduct an exploratory study into how coupons might influence learner behavior in courses targeted at educators. The providers in the first case study hosted seven instances of four different courses on the edX platform over a three-year period, where basic services were available for free, and users could pay a premium for more advanced features. In two courses and five instances, learners could access all course materials for free, but they could only earn a certificate if they upgraded to a certificate-eligible track on the edX platform, called the "verified" track, and completed all course requirements. Learners who did not purchase a verified track are referred to as auditors. In the other two courses, a donor sponsored an initiative to make a coupon code available to all learners to make the verified track free. By comparing participant behavior in the two free-certificate-eligible courses to the other course offerings, we make some preliminary investigations into how MOOC consumers respond to discounts, subject to the limitations of cross-sectional research.

In the second case study ( $\mathrm{N}=474$ registrants), we examine an online professional certification program on quantum computing that used Open edX software. The courses in the certification program had highquality content and a higher price, and they targeted professional learners. They were restricted to learners who pay the course fees. One cohort of learners was able to access the program for free because the courses were sponsored by their employer. This group of free-certificate track-eligible learners will be used as a comparison group for the rest of learners who paid for the quantum computing courses. Our overall objectives are, first, to compare in each of the case studies the potential effect on engagement and completion of being able to obtain certificates without having to make a financial investment in a course and, second, to make some cross-case observations.

The remainder of the article is organized as follows. The "Background" section reviews related work on education, price elasticity, and commitment devices. The "Methods" section describes the context and design of each study, research questions, and data collection. The "Results" section delves into the results of each case study. And the "Discussion" section finalizes the paper with discussion, limitations, and directions for future work. 


\section{Background}

This work builds on two ideas from economics and marketing research-elasticity and commitment devices-that have received limited attention in the literature on MOOCs and other consumer-oriented online learning experiences.

Elasticity refers to the slope of a demand curve in a basic supply- demand model. In some domains, goods are inelastic or minimally sensitive to price; demand declines slowly as price increases (e.g., gasoline). In the case of elastic demand, demand declines very rapidly as price increases (and vice versa). Studies of higher education have found that student demand for higher education is highly elastic (Heller, 1997; Leslie \& Brinkman, 1987). Moreover, tuition subsidies can dramatically improve college attendance and graduation rates. For example, a study of the Social Security benefit program, which provided college tuition subsidies for students with deceased parents, found that a US $\$ 1,000$ subsidy increased college attendance by four percentage points and educational attainment by 0.16 years (Dynarski, 2001). Another study found that students who just met the high school grade point average eligibility cutoff for an in-state college tuition subsidy took more credit hours and were more likely to graduate than comparable students just below the cutoff (Henry, Rubenstein, \& Bugler, 2004).

Although extensive work has been done in higher education to calculate the optimum value of tuition fees (Bryan \&Whipple, 1995), these ideas have not been extensively applied to MOOCs. Studies of MOOCs have explored other influences on students' demand for courses. One study used Google Trends and the Baidu Index for China to build a model that could act as a proxy for MOOC demand (Tong \& Li, 2018). The authors found that higher unemployment promoted MOOC demand and that in OECD countries, higher education participation was also positively correlated with MOOC demand. These findings might be a starting point from which to adapt pricing according to MOOC demand. It would be favorable for the providers if the price of every course could be optimized so that the highest willingness to pay (WTP) of a majority of the students meets the lowest willingness to accept (WTA) of the provider (Shi, Li, Haller, \& Campbell, 2018). Experiments with coupons and variable pricing can help measure consumer price sensitivity in this new sector.

Behavioral economics researchers have also noted that financial investments can serve as commitment devices (Rogers, Milkman, \&Volpp, 2014). A commitment device is a voluntary constraint on future choices to encourage a specific behavior. The theory is that consumers are trying to reduce what economists call hyperbolic discounting: the tendency to value short-term rewards more than long-term gains (Laibson, 1997; Rabin \& O’Donoghue, 1999). By investing in a commitment device, consumers make the short-term rewards more expensive, making it more likely they will engage in behavior that creates long-term gains (John, 2019).

Educational costs, for example, the cost of a course certificate, are potentially effective commitment devices. By prepaying for a course certificate, learners increase the cost of quitting the course. Additionally, they may also be motivated to finish the course to avoid a "sunk cost" (Garland, 1990) due to the negative emotions associated with paying for something they do not end up using. However, if the penalty selected 
by the consumer is too low, then the commitment device is unlikely to be strong enough to alter immediate preference for short-term rewards (J ohn, 2019).

Research on the effect of education costs as commitment devices have been mixed. On the one hand, one study found that students just above the threshold for receiving full scholarships for in-state universities had lower college completion rates than students who were just below the full scholarship threshold and thus were less likely to attend in-state universities (Cohodes \& Goodman, 2014). The authors of that study also posit that scholarships encouraged students to attend lower-quality schools, which may have affected completion rates. In another study, students were randomized into free, large-discount, small-discount, and no-discount conditions for an extracurricular tutorial at a Dutch university (Ketel, Linde, Oosterbeek, $\&$ van der Klaauw, 2016). The study did not find any significant relationship between receiving the course for free or at a discount and students' attendance or grades.

Within MOOCs, purchasing entry into a certificate-eligible track substantially increases completion rates. For example, in HarvardX and MITx courses, completion rates among participants averages 7.7\%, but completion rates for verified participants average 60\% (Chuang \& Ho, 2016). However, few studies have explored whether the amount paid for a course, rather than simply having access to a verified track, is related to course engagement and completion. One empirical study used a Web crawler to mine all prices and characteristics of edX courses (Shi et al., 2018). The authors found a positive correlation between price and the number of registrants, which may indicate that a higher price might bring about more registrations, as society often uses price as a proxy of quality (Armstrong, 2014). However, they did not find a correlation between course persistence or completion rates, which would indicate that a small variance in price may not have as strong an effect as a commitment device (Shi et al., 2018).

One possibility is that the act of signing up to earn a certificate in a MOOC, rather than the cost for it, may be a factor that increases completion rates. Koch and Nafziger (2016) argue that setting a goal creates a reference point, an expectation for our future selves that makes under-performance painful. Signing up for a certificate track in a MOOC makes this expectation about their future selves explicit. When learners sign up for a certificate track, they set explicit expectations that can be later used toward motivating themselves to complete the course.

Using coupons to manipulate the price of a course can disentangle the incentivizing effect of certificate attainment from the financial investment of the learner in the course, separating the value of attempting to earn a recognized certificate from the cost of signing up for a certificate-eligible track. If the cost of a certificate acts as a strong commitment device, verified-track purchases should be positively correlated with persistence among consumers, and if the cost of a certificate is a weak commitment device, then persistence should be weakly correlated with paying for a certificate-eligible track. The two case studies in this article examine instances where specific cohorts of learners had access to coupons, which allowed them to earn a verified certificate without investing money in the course. By comparing these learners with learners in the same or similar courses, we can estimate the extent that paying for a certificate-eligible track changes its potency as a commitment device. 


\section{Methodology}

\section{Context and Study Design}

Case study 1. In the first case study, we capitalized on a philanthropic intervention of a coupon for free certificates in two courses that were offered by an instructional design team, which had offered similar courses without the intervention. We examined seven total course instances-two courses with the intervention and five instances of the other two courses without the intervention. Across all seven course runs, there were 43,526 unique user identifiers, of which only $4 \%(N=1,673)$ registered for courses in both conditions. As a result, we treat these conditions in our analyses as separate samples.

In the course instances with the intervention ( $\mathrm{N}=7,053$ registrants), philanthropists funded a coupon code, available to all registrants, which they could use to upgrade to a free verified certificate. Links to access the coupon code were distributed through e-mail messages and the course platform. In the course instances without the intervention ( $\mathrm{N}=43,400$ registrants), participants could upgrade to the verified-certificate track for US\$49. Upgrading to the verified track did not provide any additional access to content or features. However, upgrading did allow participants to earn a verified certificate if they self-reported completion of at least $60 \%$ of the course assignments and verified their identity.

Although the intervention was applied in different sets of courses, all of the courses developed by this instructional design team shared a similar pedagogical structure and participant profile. These courses were targeted at education professionals, including teachers and school leaders, librarians, principals, and system administrators. Within each unit of a course, learners watched expert presentations from course faculty, viewed case videos about schools engaging in innovation efforts, participated in activities and assignments that encouraged learners to learn about their own contexts, and took steps to launch initiatives to improve teaching and learning. These courses were offered through the edX platform and were free for participants to access. The course did not offer any additional academic or professional development credit; however, some teachers did report earning credit independently through their school or district. As a result, the only direct benefit that participants received from completing the course was a certificate of completion. Participants did receive indirect benefits from participating in the courses such as connecting with other educators and learning about new resources.

The instructional philosophy of the courses was to try to serve both learners who might only have a few minutes to browse or a few hours to explore and others that have more substantial time to fully complete a course and earn a certificate. For instance, these courses typically began with videos that summarized the most important ideas from the course in a few minutes, and subsequent course materials built upon these core ideas. A casual browser might benefit from a burst of inspiration, while a more devoted learner would develop new skills and understandings. As a result, the instructional staff worked not just to increase certification rate but to shift the entire distribution of participants toward greater activity. 
Case study 2. MIT xPRO is an independent initiative from the Massachusetts Institute of Technology (MIT) that uses Open edX software to teach private courses to professionals on topics that are emerging and have high industry appeal. Applications of Quantum Computing in MIT XPRO (QCX) is a professional certification program that focuses on the core principles, business implications, and implementation of quantum computing. This program targets professionals who are interested in learning the basis of quantum computing and how it can be applied to different contexts. Courses are designed to be four weeks long with a learner time commitment of three to five hours per week spent viewing videos, reading content, completing practice activities, and working on application/project assignments. The courses are self-paced, and most deadlines are flexible. Prior knowledge of quantum mechanics is helpful but not required. The fees to take the four QCx courses were US $\$ 3,900$. If courses were taken separately, the price was US\$1,700 for each one.

The four courses of the first iteration of this program took place between April 2018 and October 2018 with 133 unique users and 474 users by course. These courses were sponsored by IBM Research, and as part of the agreement, IBM was able to provide free access to these courses to some of their employees; we describe this cohort of IBM employees who accessed these courses for free as brand ambassadors. Brand ambassadors ( $\mathrm{N}=32$ unique users, 127 users by course) were able to earn a certificate without having to pay the required course fees. To the best of our knowledge, we are not aware of any incentives or penalties offered by IBM related to course completion that could bias the results. The rest of the participants $(\mathrm{N}=101$ unique users, 347 users by course) were mainly researchers, managers, or executives working in industries that could benefit from the application of quantum computing topics. To the best of our knowledge, no other participants' companies offered incentives or subsidies for participating in the courses, and only learners who worked for IBM Research were able to participate in the courses for free.

In order to be consistent with our methodology in Case Study 1, and because participants could register for each course separately, we use user by course as the unit of analysis in all of our analyses.

Comparisons across cases. The two cases explored in this paper differ in terms of course content, types of participants, and pricing strategies. In Case Study 1, the courses were targeted at educators, and the cost of participating in the certificate-eligible track was nominal (US\$49). The opportunity to earn a free certificate was offered in two courses and was available to all learners. In Case Study 2 , the courses were designed as an online professional certification program on quantum computing, with all four courses costing US $\$ 3,900$, and entry was restricted to only those who paid the course fees.

However, because both courses used Open edX and thus shared a similar data structure, we were able to analyze the same variables within each set of courses. Additionally, the stark differences in the value of the coupons between the two case studies allow us to explore the extent that the amount of price reduction is related to changes in learner behavior. Finally, by analyzing cases in two very different contexts, we can infer more generalizable principles than if we examined case studies within similar contexts (Yin, 2003).

\section{Research Questions}

1. How did eligibility for a free-certificate track affect the percentage of students who verified for the courses (Case Study 1 only) and the demographics of those participants? 
2. How did eligibility for a free-certificate track affect participants' intentions to participate in the course as reported on entrance surveys?

3. Accounting for differences in course content and length, did free-certificate track participants have different outcomes than paid-certificate track participants in the following:

- number of events in the course,

- number of videos watched,

- number of days participating in course,

- course grades, or

- completing the course (e.g., earning a $60 \%$ or higher in the course)?

\section{Data and Methods}

We downloaded the standard edX data packages and log files for all the courses from the respective MITx and MIT xPRO case studies. Since both platforms run on the Open edX learning environment, we were able to use edx2bigquery data processing scripts (Lopez, Seaton, Ang, Tingley, \& Chuang, 2017) to arrange the data in a person-course data set that contains columns regarding course activity and completion of the learner with the course. The person-course data set also contains a column representing the modal country of the user (based on IP address). Additionally, we merged in participant gender, date of birth, and level of education, which were collected when participants registered for the platform.

Both courses administered entrance surveys to all course participants. Using participants' unique identifiers, we were able to merge their survey responses with the person-course data set. For this analysis, we focus on survey questions on intentions to participate in the course as reported in the entrance surveys. Although participants' intentions have historically not been strong predictors of MOOC course participation (Campbell, Gibbs, Najafi, \& Severinski, 2014), we chose to analyze intentions because we were interested in comparing participants' mind-sets on the outset of the course to detect possible differences in intentions. Response rates for the entrance surveys were 60\% among verified participants in Case Study 1 and 51\% across all learners in Case Study 2.

In the first case study, we flagged whether each user signed up for the verified track. In the second case study, where all users were in a verified track, we flagged whether each user was an IBM brand ambassador and could access the course for free. For each user, we identified whether the user earned a certificate, the number of events in the course, the number of videos watched, the number of active days, and the user's course grade. To account for different content and course lengths in the study, we calculated z-scores for each of the course activities within each individual course. This method, which is often used in studies comparing student performance in different academic courses (e.g., see Blazar, 2018), allows for comparisons across courses without having to make the assumption that distributions are equivalent across courses. One challenge in analyzing MOOC data is that a large percentage of participants who register never click into the course, leading to a lot of zero values for course outcomes. As a result, in both analyses, we 
restricted the regression analyses to participants who viewed (i.e., clicked into the course) the course at least once during the time the course was active (Case Study 1, $N=21,497$; and Case Study 2, $N=408$ ).

For Case Study 1, we compared the within-course standardized difference between verified participants and auditors (i.e., participants who did not sign up for the verified track) in the five paid-certificate track courses to the same difference in the two courses with the free-certificate track coupons, controlling for gender, age, level of education, and whether the user was in the United States. The relative difference between paid and free verification is represented in the regression model by the interaction between verification and course cost (i.e., was a free-certificate track coupon available to learners?). If the financial investment of a certificate affected participation, we would expect that the difference in participation and completion between verified and auditing participants would be smaller in the free-certificate-track courses than in the courses without coupons. Alternatively, if signing up for a verified track was itself an incentive, perhaps because it served as a reference point for a future self, we would expect to observe little difference in the gap between verified and non-verified track learners in paid and free-certificate-track courses.

For Case Study 2, we compared the within-course standardized differences in activity between participants who paid the verification fee and the IBM brand ambassadors who could enroll in the courses for free, controlling for gender, age, level of education, and whether the user was in the United States. If the financial investment of a certificate affected participation, we would expect the participants who accessed course content for free to have lower levels of course activity and course completion than those who had paid to access the course content. Alternatively, if signing up to earn certificate alone was a sufficient incentive to encourage completion, perhaps because it served as a reference point for a future self, we would expect to observe few differences between paying and nonpaying students.

\section{Results}

\section{Case Study 1 Results}

In Case Study 1, offering coupons for free-certificate track eligibility was associated with more students signing up for a verified certificate. In the paid-certificate track courses, 3\% of participants paid for the verified track $(\mathrm{N}=1,439)$, which allowed them to earn a verified certificate-similar to the overall percentage of verified users in MITx and HarvardX courses (Chuang \& Ho, 2016). In the free-certificatetrack courses, the percentage of users who signed up for the verified track was $13 \%(\mathrm{~N}=950)$, four times the rate of the paid-certificate track courses. Table 1 presents the demographics of verified participants in the free-certificate-track and paid-certificate-track courses from Case Study 1. Verified participants in the free-certificate-track courses were more likely to be from the United States $(p<.001)$, but no significant differences by age, gender, or level of education were observed. 
Table 1

Case Study 1: Demographics of Verified Users in Free- and Paid-Certificate-Track Courses

\begin{tabular}{ccc}
\hline & Paid certificate (\%) & Free certificate (\%) \\
\hline Female & 55 & 56 \\
Male & 45 & 44 \\
$<30$ & 15 & 15 \\
$30-39$ & 31 & 34 \\
$40-49$ & 32 & 29 \\
$50-59$ & 18 & 18 \\
$60-69$ & 4 & 4 \\
$70+$ & 1 & 0 \\
High school or less & 3 & 3 \\
Associate's degree & 2 & 1 \\
Bachelor's degree & 27 & 25 \\
Master's degree & 59 & 60 \\
Doctoral degree & 9 & 12 \\
In United States & 37 & 57 \\
Outside United States & 63 & 43 \\
\hline
\end{tabular}

Learners in both the courses with the free-certificate track and courses with only a paid-certificate track had similar intentions to participate in the course. On the pre-survey, participants were asked what proportion of course assessment they intended to complete on a labeled four-point scale, where a four indicated "all assessments." Verified learners in the free-certificate track courses were similarly likely to report that they intended to complete all assessments (76\% for paid-certificate track vs. $75 \%$ for freecertificate track), while auditors in both tracks were less likely to report that they intended to complete all assessments ( $53 \%$ for paid-certificate track vs. $44 \%$ for free-certificate track; see Figure 1 ). Using an analysis of variance (ANOVA) model, we found significant differences between groups of learners in intentions to complete assessments, with post hoc tests indicating significant mean differences between the verified learners and auditors in both the paid-certificate (3.37vs. 3.73, p <.001) and free-certificate-eligible-track courses (3.20 vs. 3.72, $p<.001)$ but not between the two groups of verified learners ( $p>1)$. 


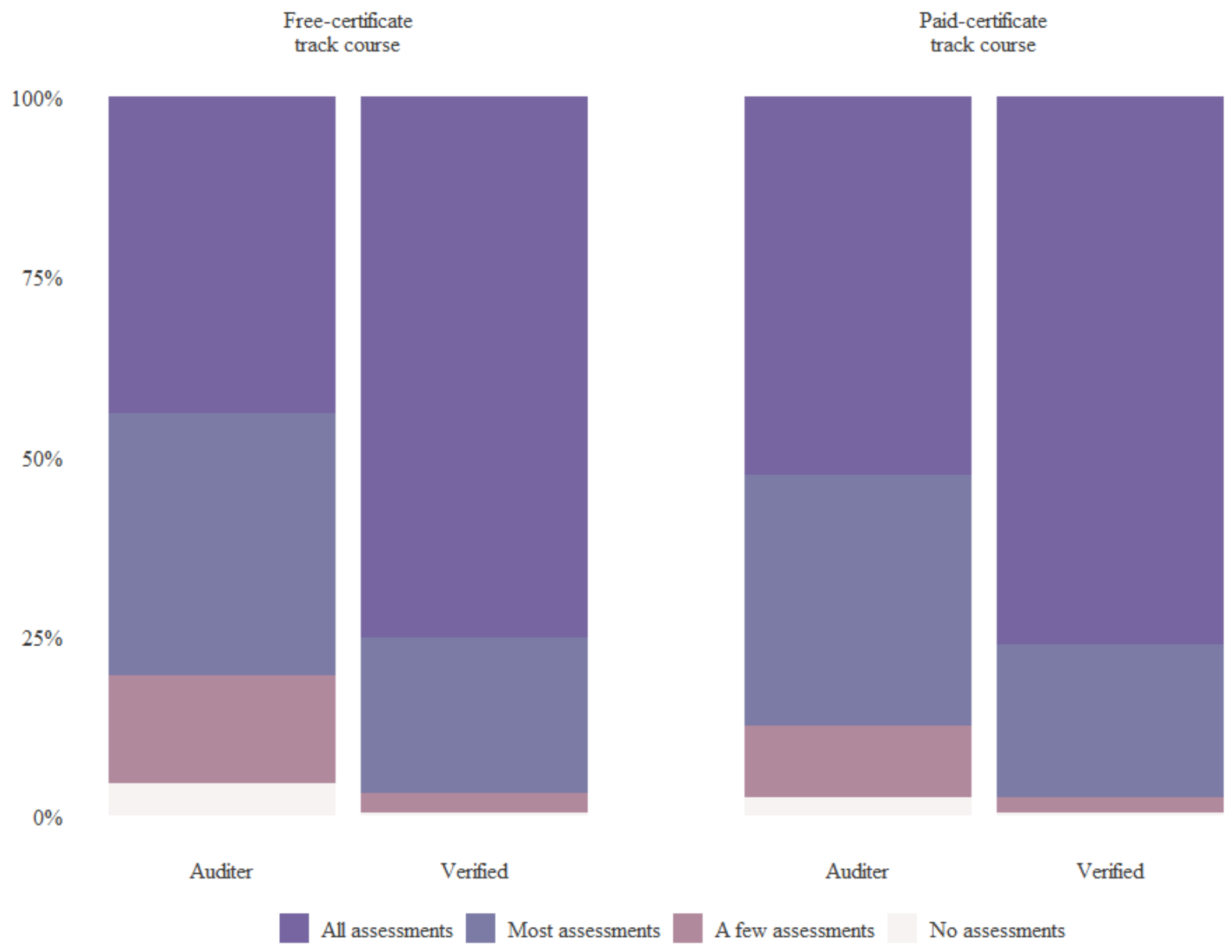

Figure 1. Case study 1: Assessment completion intentions on entrance survey.

The regression results for course participation indicators and grades are reported in Figure 2. Verified students had higher engagement in the courses than auditors. Compared with auditors, verified students recorded 1.75 standard deviation $(S D)$ more events $(p<.001)$, watched 1.62 SD more videos $(p<.001)$, and spent 1.75 SD more days in the course $(\mathrm{p}<.001)$. Verified students also had course grades that were 1.35 SDs higher than auditors $(\mathrm{p}<.001)$. Because outcomes were standardized within courses, the value of a $1 \mathrm{SD}$ difference varied by course. On average, a $1 \mathrm{SD}$ increase was the equivalent of 288 more events, 10 more videos watched, 4 more active days, and a 31-point increase in grades. The full regression tables for all analyses can be found in the appendix. 


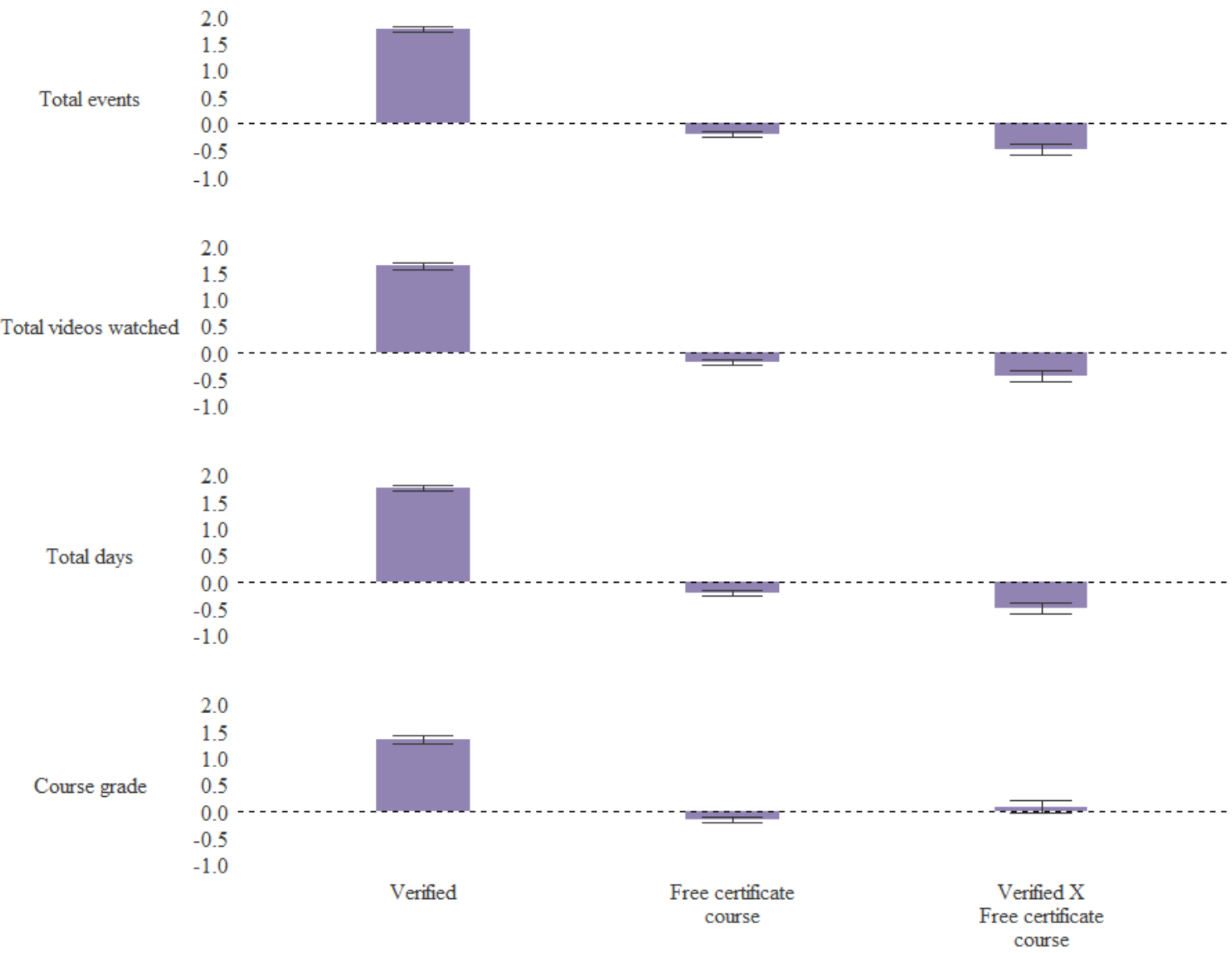

Figure 2. Case study 1: Regression estimates.

Additionally, verified students in the free-certificate track courses continued to have higher levels of course engagement than students who audited the course, but the difference between these two groups was significantly smaller in the free-certificate-track course than in the paid-certificate-track courses. On average, the difference between verified and auditing students was 0.51 to 0.45 SDs smaller in the freecertificate-track course than in the paid-certificate-track courses $(p<.001)$. The differences in course grades were greater, but not statistically significantly, in the free-certificate-track course than in the paidcertificate-track courses (0.075 SDs, $\mathrm{p}>$.1).

Course completion rates were higher in the free-certificate-track courses than in the paid-certificate-track courses. In the free-certificate-track courses, $47 \%$ of verified students passed the course $(\mathrm{N}=442)$ and earned a certificate, while $41 \%$ earned a certificate in the paid-certificate-track courses $(\mathrm{N}=593, \mathrm{p}<.05)$. Overall, there was less activity in the course when learners could access free certificates but also slightly higher rates of certification.

\section{Case Study 2 Results}


Table 2 presents the demographic characteristics of participants in Case Study 2 by certificate track ( $\mathrm{N}$ =474). Participants who were eligible for a free-certificate track were more likely to be female, have an advanced degree (particularly a doctoral degree), and be over theage of 50 ( $p<.001$ ), and they were slightly more likely to be in the United States, although this difference was not statistically significant $(p>.1)$.

Table 2

Case Study 2: Demographics of Verified Users in Free- and Paid-Certificate-Track Courses

\begin{tabular}{ccc}
\hline & Paid certificate (\%) & Free certificate (\%) \\
\hline Female & 8 & 27 \\
Male & 92 & 73 \\
$<30$ & 12 & 0 \\
$30-39$ & 32 & 21 \\
$40-49$ & 37 & 39 \\
$50-59$ & 9 & 36 \\
$60-69$ & 5 & 4 \\
$70+$ & 4 & 0 \\
High school or less & 3 & 0 \\
Associate's degree & 0 & 0 \\
Bachelor's degree & 21 & 7 \\
Master's degree & 45 & 21 \\
Doctoral degree & 31 & 72 \\
In United States & 59 & 63 \\
Outside United States & 41 & 37
\end{tabular}

On entrance surveys, learners in the free-certificate track were slightly less likely than those in the paidcertificate track to say that "earning a certificate" was an important motivation for completing the course $(p<.1)$. Yet for many participants in the free-certificate track, earning a certificate was an important motivator; 37\% said that earning a certificate was a "very" or "extremely" important motivation for them in participating in the QCx courses, compared with $48 \%$ of those in the paid-certificate track (Figure 3 ). 


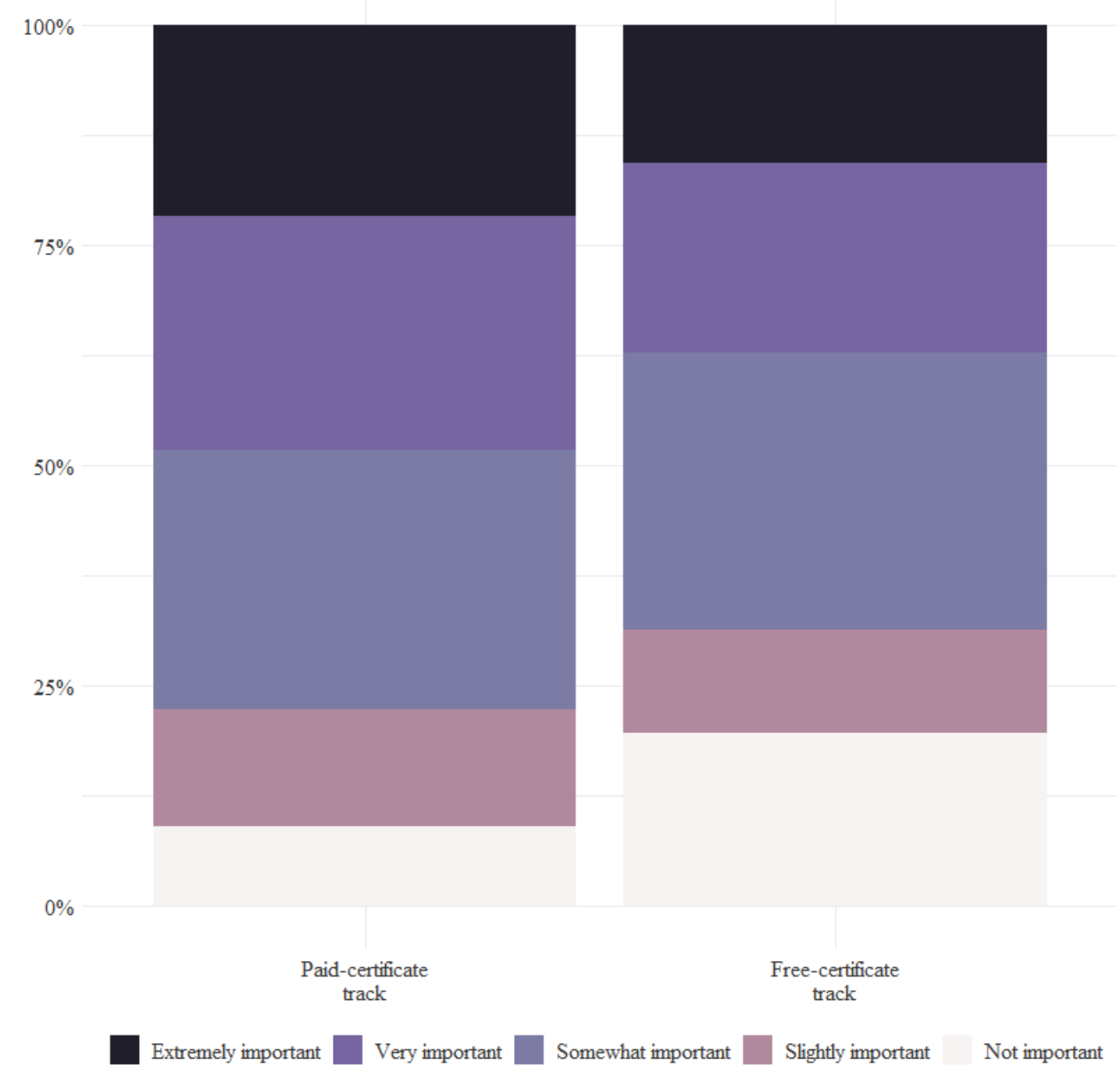

Figure 3. Case study 2: Importance of earning a certificate on entrance survey.

The regression results for Case Study 2 are reported in Figure 4. Learners in the free-certificate track had, on average, $0.44 \mathrm{SD}$ fewer events than students in the paid-certificate track $(\mathrm{p}<.05)$. Free-certificate track students also watched fewer videos (0.25 SDs) and had fewer active days (0.20 SDs), although the differences were not statistically significant ( $p>$.1). No meaningful difference was found in course grades between students in the two tracks (0.05 SDs, $p>$.1). As in Case Study 1, the value of a 1 SD difference varied by course. On average, a 1 SD increase was the difference of 3,763 events, 12 videos watched, 39 days in the course, and a 6.3-point increase in grades.

Although completion rates were generally high, students in the free-certificate track had lower completion rates $(50 \%)$ than those who paid for a certificate $(77 \%, \mathrm{p}<.001)$. However, a significant portion of noncompleters among free-certificate track students never clicked into the course $(26 \%, \mathrm{~N}=33)$. When 
restricted to only those learners who had clicked into the course, the gap in completion was smaller (68\%$85 \%, \mathrm{p}<.001)$.

As we found in Case Study 1, in Case Study 2, free-certificate-track coupons were associated with lower overall learner activity compared with learners who paid the course fees. However, in this case study, we did observe lower-though not remarkably so-completion rates. Consequently, the possibility of earning certificates for free might somewhat diminish learners' motivation to be highly active in the course; however, even those who were in the free-certificate track participated and completed the course at relatively high rates.

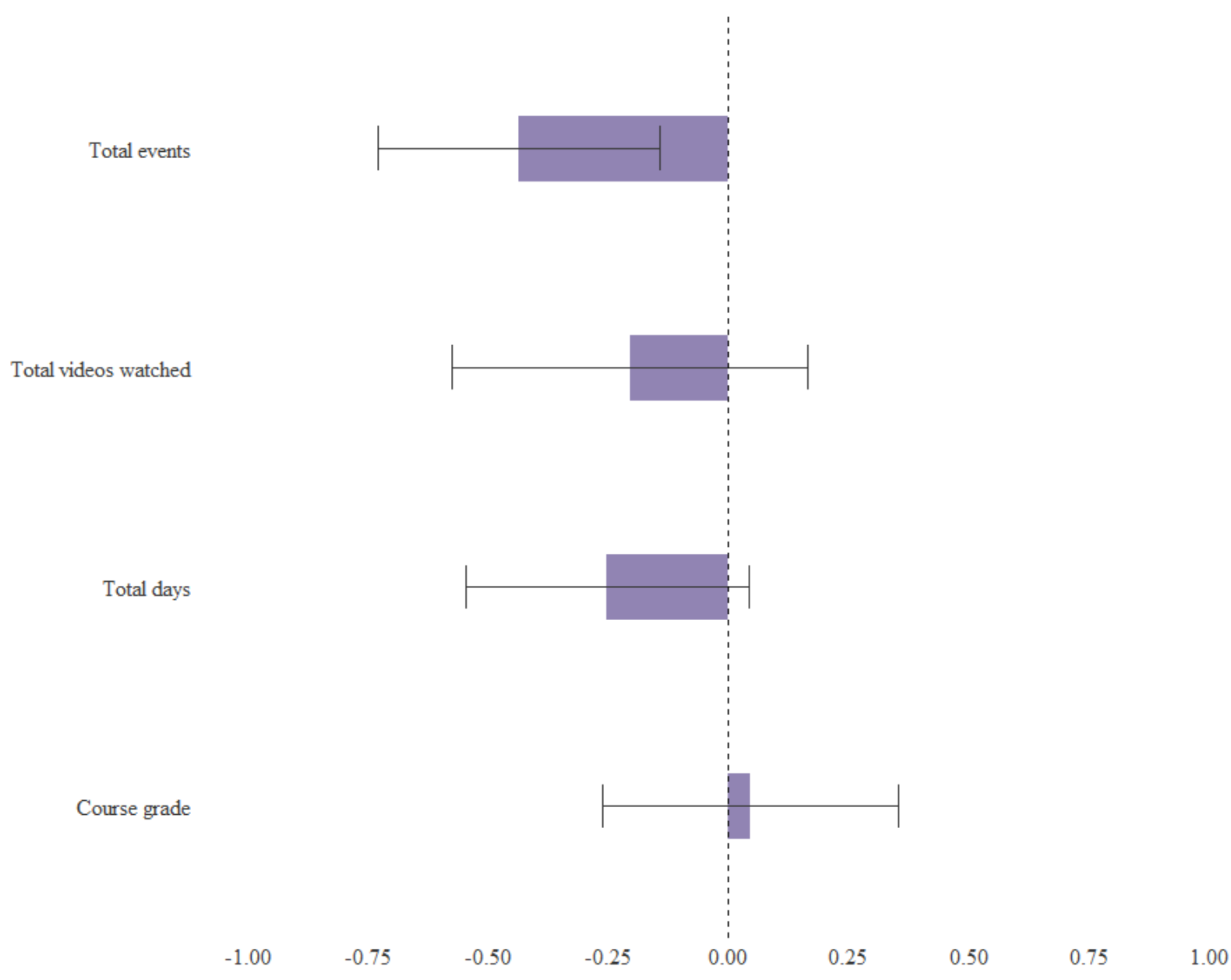

Figure 4. Regression estimates for Case Study 2.

\section{Discussion}

This work reports on a pair of online learning case studies, where participants had the opportunity to earn a free certificate, to explore how the price of a certificate is associated with changes in student enrollment 
and activity. Specifically, we were interested in whether reducing the cost of a certificate to $\$ 0$ would be linked to an increase in the number and type of students who enrolled in a verified track. We also examined whether participants who did not pay for a certificate were less engaged in the course since they lacked the commitment device of having invested money.

Our findings suggest that consumers of MOOC-based technologies are price-sensitive; a reduction of only US\$49 in cost was linked to a quadrupling in the percent of verified registration in Case Study 1. Additionally, in Case Study 2, when the cost of the course was US\$3,900, more women, participants over theage of 50, and participants in the United States participated in the free-certificate track than in the paidcertificate track. This suggests that these participants may be particularly price-sensitive and thus more likely to sign up for a certificate track if it is free.

Our findings also suggest that the opportunity to earn a certificate, whether or not the learner invests in the course, may serve as its own commitment device. In Case Study 1, participants reported that motivation to participate in the courses were similar across the paid- and free-certificate-track courses, and the completion rates were almost identical. In Case Study 2, while both intentions to earn a certificate and completion rates were lower in the free-certificate track than in the paid-certificate track, still more than half of the participants completed the course. Although course participation was lower among students in the free-certificate track, in both case studies, participation and completion among verified students in the free-certificate track was very high. We might view the process of signing up for a verified certificate and financial investment in the course as two separate mechanisms for encouraging commitment within an online course. The fact that we observed similar trends in both case studies, despite the vast differences in settings, suggests that similar underlying mechanisms may be responsible for promoting course participation. Participants may be influenced not only by the amount of money they invest in a course but also by concern for not meeting the reference point-that is, the expectations they set for themselves (Koch \& Nafziger, 2016) - by signing up for the certificate track.

These findings suggest that offering free-certificate coupons can be an effective way to increase participation in online learning. This may be especially useful for groups of learners who are particularly price-sensitive, such as low-income learners, and who may not be willing or able to pay the full price for a certificate. MOOC instructional designers may wish to experiment with offering free or discounted certificates to such leaners to encourage wider participation in their courses and encourage completion. These findings may also be relevant to other open and distant learning contexts where course developers seek to maximize participation among underserved and price-sensitive groups of participants.

The findings of our study have a number of limitations. The first is that our case studies are observational in nature. Participants were not randomly assigned to receive coupons for free-certificate tracks. In Case Study 1, all participants in two courses were offered the opportunity to redeem a coupon to sign up for the verified track. In Case Study 2, a select group of participants were given access to the course for free because their employer sponsored the course. As a result, participants in the free-certificate-track condition in both case studies may have had systematically different backgrounds and motivations than those in the paidcertificate-track condition. Although we controlled for demographic differences in our statistical models, the two groups possibly differed in other unobserved characteristics. 
Our study provides cross-sectional evidence that can motivate further work that supports more robust causal inference. Researchers should identify how consumers of MOOC-based technologies respond to different incentives across different courses and contexts. Experimental designs could randomly assign registrants to receive a coupon by e-mail or in the courseware, or a more sophisticated design could be used across a set of courses that is randomized at the course level. However, in using such designs, researchers may need to consider ways to minimize the disruption of having only some students in the course receive a subsidized certificate. More nuanced approaches might randomly assign students to receive coupons for part of the cost to see if there is an optimization point that substantially reduces cost while including a small, symbolic investment as a commitment device. Researchers may also want to experiment with conditions where signing up for a certificate is explicitly tied to reference point expectations language to measure the potency of reference points as commitment devices.

As governments and workforce development systems turn to online learning to support lifelong learners, better understandings of how consumers of MOOC-based technologies respond to different financial incentives can help organizations effectively target resources to optimize educational attainment.

\section{Acknowledgements}

We gratefully acknowledge the financial support of our generous donors, the instructional design teams that develop these courses, and the learners and participants in this study. 


\section{References}

Armstrong, L. (2014). Barriers to innovation and change in higher education. Retrieved from https:// www.tiaainstitute.org/publication/ barriers-innovation-and-change

Baker, R., \& Passmore, D. (2016). Value and pricing of MOOCs. Education Sciences, 6(2), 14. https:// doi.org/ 10.3390/ educsci6020014

Blazar, D. (2018). Validating teacher effects on students' attitudes and behaviors: Evidence from random assignment of teachers to students. Education Finance and Policy, 13(3), 281-309. https:// doi.org/ 10.1162/edfp a 00251

Bonvillian, W., \& Singer, S. (2013). The online challenge to higher education. Issues in Science and Technology, 29(4). Retrieved from https://issues.org/the-online-challenge-to-higher-education/

Bryan, G. A., \&Whipple, T. W. (1995). Tuition elasticity of the demand for higher education among current students: A pricing model. The J ournal of Higher Education, 66(5), 560-574. https:// doi.org/ 10.2307/2943936

Campbell, J ., Gibbs, A. L., Najafi, H., \& Severinski, C. (2014). A comparison of learner intent and behaviour in live and archived MOOCs. The International Review of Research in Open and Distributed Learning, 15(5). https:// doi.org/ 10.19173/irrodl.v15i5.1854

Chuang, I., \& Ho, A. (2016). HarvardX and MITx: Four years of open online courses-Fall 2012-Summer 2016. SSRN. https:// doi.org/ 10.2139/ssrn.2889436

Cohodes, S. R., \& Goodman, J . S. (2014). Merit aid, college quality, and college completion: Massachusetts' Adams Scholarship as an in-kind subsidy. American Economic J ournal: Applied Economics, 6(4), 251-285. https:// doi.org/ 10.1257/ app.6.4.251

Dellarocas, C., \& Van Alstyne, M. (2013). Money models for MOOCs. Communications of the ACM, 56(8), 25-28. https:// doi.org/ 10.1145/2492007.2492017

Dynarski, S. M. (2001). Does aid matter? Measuring the effect of student aid on college attendance and completion (KSG Faculty Research Working Paper Series RWP01-034). https:// doi.org/ 10.2139/ssrn.288547

Garland, H. (1990). Throwing good money after bad: The effect of sunk costs on the decision to escalate commitment to an ongoing project. J ournal of Applied Psychology, 75(6), 728-731. https:// doi.org/ 10.1037/ 0021-9010.75.6.728

Heller, D. E. (1997). Student price response in higher education. The J ournal of Higher Education, 68(6), 624-659. https:// doi.org/ 10.1080/00221546.1997.11779004 
Henry, G. T., Rubenstein, R., \& Bugler, D. T. (2004). Is HOPE enough? Impacts of receiving and losing merit-based financial aid. Educational Policy, 18(5), 686- 709.

https:// doi.org/ 10.1177/ 0895904804269098

John, A. (2019). When commitment fails-Evidence from a field experiment. Management Science, 12, 127. https:// doi.org/ 10.1287/ mnsc.2018.3236

Ketel, N., Linde, J ., Oosterbeek, H., \& van der Klaauw, B. (2016). Tuition fees and sunk-cost effects. The Economic J ournal, 126(598), 2342-2362. https:// doi.org/ 10.1111/ ecoj.12297

Koch, A. K., \& Nafziger, J . (2016). Goals and bracketing under mental accounting. J ournal of Economic Theory, 162, 305- 351. https:// doi.org/ 10.1016/J.J ET.2016.01.001

Kung, L.-C., \&Yang, P.-J . (2018). Certificate or subscription? The optimal pricing strategy of massive online open courses. In M. Hirano, M. D. Myers, K. Kijima, M. Tanabu, \&D. Senoo (Eds.), Pacific Asia Conference on Information Systems (PACIS) 2018 Proceedings (p. 301). Retrieved from https://aisel.aisnet.org/ pacis2018/301

Laibson, D. (1997). Golden eggs and hyperbolic discounting. The Quarterly J ournal of Economics, 112(2), 443-478. https:// doi.org/ 10.1162/003355397555253

Leslie, L. L., \& Brinkman, P. T. (1987). Student price response in higher education. The J ournal of Higher Education, 58(2), 181-204. https:// doi.org/ 10.1080/00221546.1987.11778239

Lopez, G., Seaton, D. T., Ang, A., Tingley, D., \& Chuang, I. (2017). Google BigQuery for education: Framework for parsing and analyzing edX MOOC data. In C. Urrea (Ed.), L@S '17: Proceedings of the Fourth (2017) ACM Conference on Learning @ Scale (pp. 181-184). New York, NY: ACM Press. https:// doi.org/ 10.1145/ 3051457.3053980

Rabin, M., \& O’Donoghue, T. (1999). Doing it now or later. American Economic Review, 89(1), 103-124. Retrieved from https:// pubs.aeaweb.org/ doi/pdfplus/ 10.1257/ aer.89.1.103

Reich, J ., \& Ruipérez-Valiente, J . A. (2019). The MOOC pivot. Science, 363(6423), 130- 131. https:// doi.org/ 10.1126/ science.aav7958

Rogers, T., Milkman, K. L., \&Volpp, K. G. (2014). Commitment devices: Using initiatives to change behavior. J AMA, 311(20), 2065-2066. https:// doi.org/ 10.1001/ jama.2014.3485

Shi, Y., Li, X., Haller, A., \& Campbell, J . (2018). Knowledge pricing structures on MOOC platform-A use case analysis on edX. In M. Hirano, M. D. Myers, K. Kijima, M. Tanabu, \&D. Senoo (Eds.), Pacific Asia Conference on Information Systems (PACIS) 2018 Proceedings (p. 181). Retrieved from https://aisel.aisnet.org/ pacis2018/181 
Tong, T., \&Li, H. (2018). Demand for MOOC-An application of big data. China Economic Review, 51(C), 194- 207. Retrieved from https:// econpapers.repec.org/RePEc:eee:chieco:v:51:y:2018:i:c:p:194$\underline{207}$

Yin, R. K. (2003). Case study research: Design and methods (3rd ed.). Thousand Oaks, CA: Sage Publications. 


\section{Appendix}

\section{Table A1}

Regression Results for Case Study 1

\begin{tabular}{|c|c|c|c|c|}
\hline & \multicolumn{4}{|c|}{ Dependent variable } \\
\hline & $\begin{array}{l}\text { No. events } \\
\text { (1) }\end{array}$ & $\begin{array}{l}\text { No. videos } \\
\text { (2) }\end{array}$ & $\begin{array}{l}\text { No. days } \\
\text { (3) }\end{array}$ & $\begin{array}{l}\text { Course grade } \\
\text { (4) }\end{array}$ \\
\hline Verified & $\begin{array}{l}1.754^{* * *} \\
(0.029)\end{array}$ & $\begin{array}{l}1.618^{* * *} \\
(0.030)\end{array}$ & $\begin{array}{l}1.751^{* * *} \\
(0.030)\end{array}$ & $\begin{array}{l}1.347^{* * *} \\
(0.038)\end{array}$ \\
\hline Female & $\begin{array}{l}0.007 \\
(0.014)\end{array}$ & $\begin{array}{l}-0.033^{*} \\
(0.015)\end{array}$ & $\begin{array}{l}-0.013 \\
(0.015)\end{array}$ & $\begin{array}{l}0.059^{*} \\
(0.023)\end{array}$ \\
\hline $30-39$ & $\begin{array}{l}0.010 \\
(0.050)\end{array}$ & $\begin{array}{l}-0.001 \\
(0.053)\end{array}$ & $\begin{array}{l}0.077 \\
(0.053)\end{array}$ & $\begin{array}{l}0.020 \\
(0.079)\end{array}$ \\
\hline $40-49$ & $\begin{array}{l}0.035 \\
(0.029)\end{array}$ & $\begin{array}{l}0.035 \\
(0.031)\end{array}$ & $\begin{array}{l}0.062^{*} \\
(0.031)\end{array}$ & $\begin{array}{l}0.015 \\
(0.046)\end{array}$ \\
\hline $50-59$ & $\begin{array}{l}0.058 \\
(0.030)\end{array}$ & $\begin{array}{l}0.081^{*} \\
(0.031)\end{array}$ & $\begin{array}{l}0.082^{* *} \\
(0.031)\end{array}$ & $\begin{array}{l}0.010 \\
(0.048)\end{array}$ \\
\hline $60-69$ & $\begin{array}{l}0.084^{*} \\
(0.039)\end{array}$ & $\begin{array}{l}0.091^{*} \\
(0.041)\end{array}$ & $\begin{array}{l}0.070 \\
(0.041)\end{array}$ & $\begin{array}{l}0.020 \\
(0.060)\end{array}$ \\
\hline $70+$ & $\begin{array}{l}0.074^{* * *} \\
(0.021)\end{array}$ & $\begin{array}{l}0.089^{* * *} \\
(0.022)\end{array}$ & $\begin{array}{l}0.095^{* * *} \\
(0.022)\end{array}$ & $\begin{array}{l}0.028 \\
(0.034)\end{array}$ \\
\hline Associate's degree & $\begin{array}{l}0.095^{* * *} \\
(0.022)\end{array}$ & $\begin{array}{l}0.102^{* * *} \\
(0.024)\end{array}$ & $\begin{array}{l}0.114^{* * *} \\
(0.024)\end{array}$ & $\begin{array}{l}-0.001 \\
(0.036)\end{array}$ \\
\hline Bachelor's degree & $\begin{array}{l}0.173^{* * *} \\
(0.026)\end{array}$ & $\begin{array}{l}0.203^{* * *} \\
(0.028)\end{array}$ & $\begin{array}{l}0.207^{* * *} \\
(0.028)\end{array}$ & $\begin{array}{l}0.052 \\
(0.042)\end{array}$ \\
\hline Master's degree & $\begin{array}{l}0.240^{* * *} \\
(0.041)\end{array}$ & $\begin{array}{l}0.302^{* * *} \\
(0.043)\end{array}$ & $\begin{array}{l}0.260^{* * *} \\
(0.043)\end{array}$ & $\begin{array}{l}0.066 \\
(0.066)\end{array}$ \\
\hline Doctoral degree & $\begin{array}{l}0.391^{* * *} \\
(0.082)\end{array}$ & $\begin{array}{l}0.498^{* * *} \\
(0.087)\end{array}$ & $\begin{array}{l}0.531^{* * *} \\
(0.087)\end{array}$ & $\begin{array}{c}-0.077 \\
(0.117)\end{array}$ \\
\hline In United States & $\begin{array}{l}0.068^{* * *} \\
(0.017)\end{array}$ & $\begin{array}{l}0.029 \\
(0.017)\end{array}$ & $\begin{array}{l}0.021 \\
(0.017)\end{array}$ & $\begin{array}{l}0.077^{* *} \\
(0.026)\end{array}$ \\
\hline Free-certificate course & $\begin{array}{l}-0.205^{* * *} \\
(0.025)\end{array}$ & $\begin{array}{l}-0.197^{* * *} \\
(0.026)\end{array}$ & $\begin{array}{l}-0.203^{* * *} \\
(0.026)\end{array}$ & $\begin{array}{l}0.161^{* * *} \\
(0.029)\end{array}$ \\
\hline $\begin{array}{l}\text { Verified-certificate } \\
\text { course }\end{array}$ & $\begin{array}{l}-0.487^{* * *} \\
(0.051)\end{array}$ & $\begin{array}{l}-0.447^{* * *} \\
(0.054)\end{array}$ & $\begin{array}{l}-0.510^{* * *} \\
(0.054)\end{array}$ & $\begin{array}{l}0.075 \\
(0.058)\end{array}$ \\
\hline Constant & $\begin{array}{l}-0.299^{* * *} \\
(0.030)\end{array}$ & $\begin{array}{l}-0.271^{* * *} \\
(0.032)\end{array}$ & $\begin{array}{l}-0.286^{* * *} \\
(0.032)\end{array}$ & $\begin{array}{l}0.234^{* * *} \\
(0.048)\end{array}$ \\
\hline Observations & 15,243 & 15,243 & 15,243 & 6,506 \\
\hline $\mathrm{R}^{2}$ & 0.239 & 0.199 & 0.222 & 0.262 \\
\hline Adjusted R² & 0.238 & 0.198 & 0.221 & 0.261 \\
\hline Residual SE & 0.876 & 0.922 & 0.923 & 0.910 \\
\hline F statistic & $341.546^{* * *}$ & $270.118^{* * *}$ & $309.626^{* * *}$ & $164.776^{* * *}$ \\
\hline
\end{tabular}

Note. $\mathrm{SE}=$ standard error. ${ }^{*} \mathrm{p}<.05{ }^{* *} \mathrm{p}<.01{ }^{* * *} \mathrm{p}<.001$. 
Table A2

Regression Results for Case Study 2

Dependent variable

\begin{tabular}{|c|c|c|c|c|}
\hline & $\begin{array}{l}\text { No. events } \\
\text { (1) }\end{array}$ & $\begin{array}{l}\text { No. videos } \\
\text { (2) }\end{array}$ & $\begin{array}{l}\text { No. days } \\
\text { (3) }\end{array}$ & $\begin{array}{l}\text { Course grade } \\
\text { (4) }\end{array}$ \\
\hline \multirow[t]{2}{*}{ Free certificate } & $-0.436^{* *}$ & -0.204 & -0.253 & 0.045 \\
\hline & $(0.146)$ & $(0.185)$ & $(0.147)$ & $(0.154)$ \\
\hline \multirow[t]{2}{*}{ Female } & -0.290 & -0.177 & -0.314 & 0.227 \\
\hline & $(0.172)$ & $(0.199)$ & $(0.174)$ & (0.183) \\
\hline \multirow[t]{2}{*}{$30-39$} & $-0.556^{*}$ & $-0.476^{*}$ & $0.682^{* *}$ & $0.404^{*}$ \\
\hline & $(0.226)$ & $(0.225)$ & $(0.227)$ & $(0.205)$ \\
\hline \multirow[t]{2}{*}{$40-49$} & $-0.443^{*}$ & $-0.442^{*}$ & $0.604^{* *}$ & 0.226 \\
\hline & $(0.223)$ & $(0.223)$ & $(0.224)$ & $(0.202)$ \\
\hline \multirow[t]{2}{*}{$50-59$} & 0.187 & -0.169 & 0.106 & 0.195 \\
\hline & $(0.247)$ & $(0.251)$ & $(0.249)$ & $(0.228)$ \\
\hline \multirow[t]{2}{*}{$60-69$} & 0.071 & -0.655 & 0.501 & 0.679 \\
\hline & $(0.340)$ & $(0.355)$ & $(0.342)$ & $(0.388)$ \\
\hline \multirow[t]{2}{*}{$70+$} & -0.222 & -0.576 & -0.445 & 0.232 \\
\hline & $(0.413)$ & $(0.406)$ & $(0.415)$ & (0.419) \\
\hline \multirow[t]{2}{*}{ Associate's degree } & -0.533 & 0.094 & 0.658 & 0.209 \\
\hline & $(1.052)$ & $(1.034)$ & $(1.059)$ & $(0.935)$ \\
\hline \multirow[t]{2}{*}{ Bachelor's degree } & 0.332 & -0.172 & $1.367^{* *}$ & 0.157 \\
\hline & $(0.522)$ & $(0.514)$ & $(0.525)$ & $(0.465)$ \\
\hline \multirow[t]{2}{*}{ Master's degree } & 0.130 & 0.128 & $1.372^{* *}$ & 0.208 \\
\hline & $(0.515)$ & $(0.507)$ & $(0.518)$ & $(0.458)$ \\
\hline \multirow[t]{2}{*}{ Doctoral degree } & 0.056 & 0.091 & $1.458^{* *}$ & 0.435 \\
\hline & $(0.521)$ & $(0.514)$ & $(0.524)$ & $(0.465)$ \\
\hline \multirow[t]{2}{*}{ In United States } & $0.514^{* * *}$ & 0.044 & $0.460^{* * *}$ & 0.165 \\
\hline & $(0.114)$ & (0.123) & $(0.115)$ & (0.111) \\
\hline \multirow[t]{2}{*}{ Constant } & 0.092 & 0.406 & $-1.035^{*}$ & -0.513 \\
\hline & $(0.471)$ & $(0.463)$ & $(0.474)$ & (0.419) \\
\hline Observations & 320 & 268 & 320 & 261 \\
\hline $\mathrm{R}^{2}$ & 0.164 & 0.053 & 0.114 & 0.108 \\
\hline Adjusted R² & 0.131 & 0.008 & 0.080 & 0.065 \\
\hline \multirow{2}{*}{$\begin{array}{l}\text { Residual SE } \\
\text { F statistic }\end{array}$} & 0.941 & 0.925 & 0.947 & 0.836 \\
\hline & $5.017^{* * *}$ & 1.190 & $3.307^{* * *}$ & $2.504^{* *}$ \\
\hline
\end{tabular}

Note. SE $=$ standard error.

$* \mathrm{p}<.05 .{ }^{* *} \mathrm{p}<.01$. $^{* * *} \mathrm{p}<.001$. 
Studying Learner Behavior in Online Courses With Free-Certificate Coupons: Results From Two Case Studies Joshua Littenberg-Tobias, Jose Ruiperez Valiente, and Justin Reich

Athabasca

University

(c) 